\title{
Deletion of the histone-like protein (Hlp) from Mycobacterium smegmatis results in increased sensitivity to UV exposure, freezing and isoniazid
}

Correspondence
John L. Dahl
jldahl@d.umn.edu

Received 16 September 2010

Revised 13 October 2010

Accepted 14 October 2010

\author{
Danelle C. Whiteford, ${ }^{1}$ Jesse J. Klingelhoets, ${ }^{2}$ Michael H. Bambenek ${ }^{2}$ \\ and John L. Dahl ${ }^{2}$
}

\author{
${ }^{1}$ Sigma-Aldrich, Biotech Process Development, St Louis, MO 63103, USA \\ ${ }^{2}$ Department of Biology, University of Minnesota Duluth, Duluth, MN 55812, USA
}

\section{INTRODUCTION}

Mycobacterium smegmatis is a non-pathogenic, fast-growing mycobacterial species that is a popular model for studying slow-growing mycobacterial pathogens. It is a soil-dwelling species that has also been isolated from water and vegetation found in sphagnum moss bogs (Kazda, 2000). In these environments, M. smegmatis is naturally exposed to environmental stresses that without adaptive survival mechanisms would be lethal. The lipid-rich cell envelope of Mycobacterium provides some protection against stress by acting as a barrier to the environment (Brennan \& Nikaido, 1995). However, specific stress responses allow the cell to sense environmental insults and alter gene regulation to produce cellular and physiological changes that increase resistance. In bacterial species, a class of 'histone-like' proteins has been linked to the survival of numerous environmental stresses, such as UV light (Li \& Waters, 1998; Miyabe et al., 2000), cold shock (Wada et al., 1988), heat shock (Wada et al., 1988) and lack of nutrients (Claret \& Rouviere-Yaniv, 1997).

Bacterial histone-like proteins are small, highly basic proteins that are typically found at high abundance in cells (Thanbichler et al., 2005). These proteins display

Abbreviations: $I \mathrm{NH}$, isoniazid; TEM, transmission electron microscopy. similarities to eukaryotic histones in their ability to bind DNA and influence gene regulation (Arfin et al., 2000; Parekh \& Hatfield, 1996; Swinger \& Rice, 2004). M. smegmatis possesses a histone-like protein called Hlp (also known as Hup, DNA-binding protein HU, CipMa and MDP1) (Katsube et al., 2007; Lee et al., 1998) that is encoded by locus MSMEG_2389. This protein contains an $\mathrm{N}$-terminal domain with sequence homology to the $\mathrm{HU}$ proteins of Escherichia coli (Mukherjee et al., 2008), the best-studied family of histone-like proteins in bacteria. Hlp differs from other bacterial histone-like proteins in that it contains a C-terminal domain composed of prolines, alanines and lysines, resembling the eukaryotic histone H1 family of proteins (Mukherjee et al., 2008). Both the Cterminal and $\mathrm{N}$-terminal domains of $\mathrm{Hlp}$ are involved in binding DNA with high affinity (Mukherjee et al., 2008). Homologues of the M. smegmatis hlp have been found in most mycobacterial species, including pathogens such as Mycobacterium tuberculosis and Mycobacterium leprae (Shires \& Steyn, 2001).

Hlp has been identified as the major protein upregulated during M. smegmatis dormancy (Lee et al., 1998). It has also been identified as the major cold-shock-inducible protein in M. smegmatis (Shires \& Steyn, 2001). Its homologue in M. tuberculosis, HupB, has been found to 
be upregulated by iron limitation (Yeruva et al., 2006) and by the stringent response (Dahl et al., 2003). Although HupB in M. tuberculosis is predicted to be an essential gene (Sassetti et al., 2003), Lee et al. (1998) were able to generate an $h l p$ knockout in M. smegmatis. This deletion was found to have no effect on the viability of cultures grown for 2 weeks (Lee et al., 1998), but it did affect the ability of M. smegmatis to resume growth after being subjected to a $27{ }^{\circ} \mathrm{C}$ temperature reduction (Shires \& Steyn, 2001).

Induction of $h l p$ homologues in response to stress and the apparent importance of $\mathrm{Hlp}$ in cold-shock adaptation suggest that the protein has a role in stress resistance. Because it can bind DNA and repress transcription in vitro (Matsumoto et al., 2000), it has been suggested that Hlp could be involved in regulating gene expression during a stress response (Mukherjee et al., 2008). In the current study we examined the effect of $h l p$ deletion on the longterm survival of $M$. smegmatis in liquid culture and on the survival of cells exposed to environmental and chemical stresses.

\section{METHODS}

Bacterial strains, culture media and growth conditions. All M. smegmatis liquid cultures were grown in 7H9 (Difco) medium supplemented with $0.05 \%$ Tween 80 and $0.2 \%$ (v/v) glycerol, unless otherwise stated. For the long-term viability assay, cultures were gradually starved in $1.3 \mathrm{ml}$ aliquots of $7 \mathrm{H} 9+$ Tween 80 in Sarstedt tubes with gas-impermeable O-rings and little head space, and maintained in a $37^{\circ} \mathrm{C}$ stationary incubator. At various time points, cells were gently vortexed with $0.1 \mathrm{~mm}$ diameter, sterile glass beads and serially diluted on $7 \mathrm{H} 11$ agar plates to determine c.f.u. $\mathrm{ml}^{-1}$.

Deletion of $\boldsymbol{h l p}$ from $\boldsymbol{M}$. smegmatis $\mathbf{m c}^{\mathbf{2}} \mathbf{1 5 5}$. Deletion of $h l p$ from M. smegmatis $\mathrm{mc}^{2} 155$ was performed by allelic replacement. Briefly, an approximately $700 \mathrm{bp}$ PCR product (forward primer HusmF1, 5' agtccacttaagcggcttccgggtcgtgatct- $3^{\prime}$; reverse primer HusmR1, 5'agtccatctagacgatggtgtcgacgacgttctcc- $3^{\prime}$ ), corresponding to a chromosomal region directly upstream of $h l p$, was cloned into the AflII and XbaI restriction sites on pYUB854 (Jacobs et al., 1987) on one side of a hygromycin resistance $\left(\mathrm{Hyg}^{\mathrm{R}}\right)$ cassette. Another approximately $700 \mathrm{bp}$ PCR product (HusmF2, 5'-agtccaccatggagaaggccgccgccaagaag- $3^{\prime}$; HusmR2, 5' -agtccaagatctgaccggtcgacaccaagacggta$\left.3^{\prime}\right)$, corresponding to a region directly downstream of $h l p$, was inserted into the SpeI and HindIII restriction sites on the other side of the $\mathrm{Hyg}^{\mathrm{R}}$ cassette. The resulting plasmid was named pDW150. A marker cassette containing $\mathrm{P}_{\mathrm{Ag} 85}-$ lac $Z-\mathrm{P}_{h s p 60}-s a c B$ was removed from pGoal17 (Parish \& Stoker, 2000) and inserted into the PacI site of pDW150. This plasmid, named pDW151, was then treated with $100 \mathrm{~mJ} \mathrm{UV} \mathrm{light} \mathrm{cm}^{-2}$ and electroporated into M. smegmatis $\mathrm{mc}^{2} 155$.

Following plating on 7H11 agar containing $40 \mu \mathrm{g} \mathrm{X-Gal} \mathrm{ml}{ }^{-1}$ and $50 \mu \mathrm{g}$ hygromycin $\mathrm{ml}^{-1}$, transformants were selected that represented a single-crossover event (blue $\mathrm{Hyg}^{\mathrm{R}}$ colonies). The single-crossover transformants were then patched onto $7 \mathrm{H} 11$ plates with $50 \mu \mathrm{g}$ hygromycin $\mathrm{ml}^{-1}$ and $10 \%$ sucrose to screen for loss of sucrose sensitivity and of the lac $Z$ marker. The resulting $\operatorname{Hyg}^{\mathrm{R}} \mathrm{Suc}^{\mathrm{I}}$ lac $Z^{-}$ colonies were considered double recombinants and verified for loss of $h l p$ by PCR and Southern blot analyses.

Complementation of $h l p$ was performed using the integrative plasmid pMV306 (Stover et al., 1991). An 833 bp PCR product (HusmCF, 5' cggggtaccccgaattcgccgcccacct- $3^{\prime}$; HusmCR, 5'-cgcggatcccggcgtgcct- tttgcggaat- $3^{\prime} ; K p n I$ restriction sites indicated by bold type) was generated to include both the entire $h l p$ gene and approximately $150 \mathrm{bp}$ upstream of the predicted translation start site. The PCR conditions were $94{ }^{\circ} \mathrm{C}$ for $3 \mathrm{~min}$, and then 30 cycles of $94{ }^{\circ} \mathrm{C}, 30 \mathrm{~s}$; $54{ }^{\circ} \mathrm{C}, 1 \mathrm{~min}$; and $72{ }^{\circ} \mathrm{C}, 1 \mathrm{~min}$. A final extension step of $72{ }^{\circ} \mathrm{C}$ for 7 min was included. This PCR product was then inserted into the $K p n \mathrm{I}$ and BamHI sites on pMV306 to create the construct for complementation called pMV306/hlp. This construct was electroporated into $M$. smegmatis $\Delta h l p$, where it integrated onto the chromosome to generate M. smegmatis $\Delta$ hlp::pMV306/hlp.

Confirmation of $\boldsymbol{h l p}$ deletion from $\boldsymbol{M}$. smegmatis. To confirm the loss of $h l p$, Southern blot analysis was performed as previously described (Sambrook et al., 1989). Genomic DNA from both M. smegmatis $\mathrm{mc}^{2} 155:: \mathrm{pMV} 306$ and $\Delta h l p:: \mathrm{pMV} 306$ was digested with NotI and ScaI for 24 h before separation by gel electrophoresis and transfer to a nylon membrane. A $306 \mathrm{bp}$ PCR product (HusmPrF, 5' -cgacatcttccgggggaacg- $3^{\prime}$; HusmPrR, 5' -ccggatcaggccgggagagt $\left.-3^{\prime}\right)$ was amplified from the region directly upstream of the $h l p$ gene on the M. smegmatis chromosome. This product was then used as a template for a PCR using a Digoxigenin (DIG) labelling kit (Roche). This reaction incorporated DIG-labelled dUTP into the PCR product, generating a probe for Southern blotting. This probe was allowed to hybridize membrane-bound DNA, and detection of the probe was performed using a Nitro-Blue tetrazolium chloride/5bromo-4-chloro-3'-indolyphosphate $p$-toluidine salt (NBT/BCIP) chromogenic reaction, as previously described (Wei et al., 2000).

In addition to Southern blot analysis, deletion of $h l p$ from the $M$. smegmatis chromosome was confirmed by PCR using primers that amplified a 208 bp internal region of hlp (HlpsmIntF, 5' -cgggttcggtgtcttcgagca-3'; HlpsmIntR, 5'-ggccttcttggcgggaccag-3'). As M. smegmatis $\Delta h l p$ was generated using an allelic replacement strategy, this PCR was used to confirm the absence of the internal region of $h l p$ from the chromosome. Coomassie-stained SDS-PAGE of lateexponential phase cultures was used to confirm the loss of the Hlp protein from M. smegmatis $\Delta h l p$.

Transmission electron microscopy (TEM). TEM analysis was performed as previously described (Arora et al., 2008). Two-week-old colonies were swabbed off 7H11 agar and suspended in PBS. Cell suspensions were spotted onto Formvar carbon-coated nickel grids, which were stained with $1 \%$ uranyl acetate before viewing with a JEOL TEM 1200 EX electron microscope.

UV exposure. Aliquots $(1 \mathrm{ml})$ of $M$. smegmatis cells grown to midexponential phase $\left(\mathrm{OD}_{600}\right.$ 0.6) were placed into sterile Petri dishes and exposed to increasing amounts of UV (5.0-15.0 $\left.\mathrm{J} \mathrm{m}^{-2}\right)$ using a Bio-Rad GeneLinker UV box. Serial dilutions of treated cells were immediately performed and plated onto $7 \mathrm{H} 11$ agar. Results were reported as percentage survival compared with samples untreated with UV light.

Isoniazid (INH) sensitivity assays. Sensitivity to INH (Sigma) was examined using both the Kirby-Bauer technique and determination of MIC. First, disks soaked with concentrations of INH from 0-20 $\mu \mathrm{g}$ $\mathrm{ml}^{-1}$ were placed on a lawn of cells swabbed from early exponentialphase cultures $\left(\mathrm{OD}_{600} 0.2\right)$. After $48 \mathrm{~h}$ of incubation, diameters of the zones of inhibition were measured. The MIC was determined as described by Wallace et al. (1986). Briefly, cultures were grown to $\mathrm{OD}_{600} 0.2$ before diluting 1000 -fold and placing $50 \mu \mathrm{l}$ aliquots in triplicate into 96-well round-bottomed plates. Decreasing concentrations of INH $\left(80-0.156 \mu \mathrm{g} \mathrm{ml}^{-1}\right)$ were then added to the wells in $50 \mu \mathrm{l}$ aliquots. Following a $48 \mathrm{~h}$ incubation period, wells were examined using a dissecting microscope for growth or no growth. Sensitivities to rifampicin, ethambutol and kanamycin were also tested using the two methods described above. 
Freeze-thaw assay. $M$. smegmatis cultures were grown to $\mathrm{OD}_{600} 0.6$ in $7 \mathrm{H} 9+$ Tween 80 . Aliquots $(200 \mu \mathrm{l})$ were transferred to $1.8 \mathrm{ml}$ cryovial tubes and frozen at $-80{ }^{\circ} \mathrm{C}$ before removal and immediate thawing in a $37{ }^{\circ} \mathrm{C}$ water bath. This pattern was repeated 20 times before cells were serially diluted and plated onto $7 \mathrm{H} 11$ agar. c.f.u. were enumerated after 4 days growth and the percentage survival was calculated.

Incubation of $\boldsymbol{M}$. smegmatis in a sphagnum moss bog. Cryovial tubes containing $1.3 \mathrm{ml}$ aliquots of $M$. smegmatis strains in $7 \mathrm{H} 9+$ Tween 80 were buried $20 \mathrm{~cm}$ deep in the brown layer of a local sphagnum moss bog ( $46^{\circ} 58.557^{\prime}$, W $\left.092^{\circ} 11.804^{\prime}\right)$ for several months in 2009-2010. On the 15th of each month, three vials of each strain were extracted from the bog and viable bacteria determined by enumerating c.f.u. $\mathrm{ml}^{-1}$ on $7 \mathrm{H} 11$ agar plates. This bog is located 5 miles from Duluth International Airport and daily surface temperatures are recorded there for submission to the National Oceanic and Atmospheric Administration (NOAA)

Acid-stress assay. Sensitivity of the M. smegmatis strains to low $\mathrm{pH}$ was determined by a method similar to that described by O'Brien et al. (1996). Briefly, cells were grown in Sauton's medium with $0.05 \%$ Tween 80 adjusted to a $\mathrm{pH}$ of 6.8 . At early exponential phase $\left(\mathrm{OD}_{600} 0.015\right)$, cells were resuspended in $1 \mathrm{ml}$ aliquots of either fresh Sauton's ( $\mathrm{pH}$ 6.8) or Sauton's medium with a $\mathrm{pH}$ adjusted to a value of 5.0 or 4.0. Serial dilutions were performed on the $\mathrm{pH} 6.8$ sample to determine c.f.u. $\mathrm{ml}^{-1}$ at the initial time point $(0 \mathrm{~h})$, which was designated $100 \%$ survival. Samples were incubated for 1 day or 5 days before determining the c.f.u. $\mathrm{ml}^{-1}$ of each sample.

\section{RESULTS}

\section{Deletion of $h l p$ from $M$. smegmatis $\mathrm{mc}^{2} 155$}

Deletion of the $h l p$ gene was completed by allelic replacement with a $\mathrm{Hyg}^{\mathrm{R}}$ cassette. This replacement was confirmed by Southern blotting (Fig. 1a). The labelled probe bound to a $2.125 \mathrm{~kb}$ band in the digested DNA from M. smegmatis $\mathrm{mc}^{2} 155$ and a $3.537 \mathrm{~kb}$ band in the DNA from the mutant strain. The larger product in the mutant strain corresponds to an expected increase in size due to the replacement of the hlp gene with the $\mathrm{Hyg}^{\mathrm{R}}$ marker.

PCR analysis showed the absence of an internal region of $h l p$ in the chromosome of M. smegmatis $\Delta h l p$ (Fig. 1b). A nonspecific PCR product (upper band) served as an internal control. Absence of an $h l p$-specific PCR product from $M$. smegmatis $\Delta h l p$ corresponds with production of a $\mathrm{Hyg}^{\mathrm{R}}$ specific PCR product that was not generated from $\mathrm{mc}^{2} 155$ (data not shown). Loss of the Hlp protein was also demonstrated by SDS-PAGE (Fig. 1c). Late exponentialphase cultures of M. smegmatis $\Delta h l p::$ pMV306 lacked an approximately $30 \mathrm{kDa}$ protein (Fig. 1c, lane 3) that was present in $\mathrm{mc}^{2} 155::$ pMV306 (lane 1) and $\Delta h l p::$ pMV306/ $h l p$ (lane 2). Despite its predicted size of $21 \mathrm{kDa}$, Hlp has been shown to migrate more slowly on SDS-PAGE due to its highly basic nature (Lee et al., 1998; Shires \& Steyn, 2001).

\section{Loss of hlp alters cell and colony morphology}

Young colonies of the different strains showed marked differences in size. After 3 days growth, individual wild-type (a)

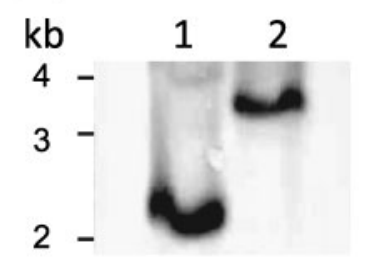

(b)

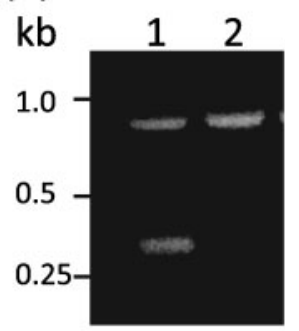

(c)

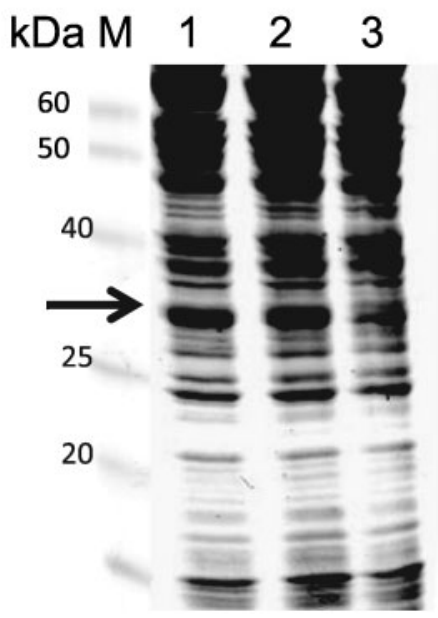

Fig. 1. Confirmation of $h / p$ deletion in M. smegmatis. (a) Southern blot analysis shows that the probe for a DNA sequence flanking $h / p$ binds to a $2.125 \mathrm{~kb}$ chromosomal fragment in the wild-type $\mathrm{mc}^{2} 155$ strain (lane 1 ). For the $\Delta h / p$ strain, this probe anneals to a fragment $1.4 \mathrm{~kb}$ larger, indicating the presence of the $\mathrm{Hyg}^{\mathrm{R}}$ cassette within $h / p$ (lane 2). (b) PCR reveals that a 200 bp internal region of $h / p$ present in $\mathrm{mc}^{2} 155$ (lower band in lane 1 ) is absent from the $\Delta h / p$ strain (lane 2). The upper band in lanes 1 and 2 is a non-specific PCR product that serves as an internal control. (c) Coomassie-stained $12 \%$ SDS-PAGE of late exponential-phase cultures demonstrates elevated levels of Hlp protein (arrow) in $\mathrm{mc}^{2} 155::$ pMV306 (lane 1) and the complemented mutant strain $\Delta h / p:$ : pMV306/h/p (lane 2), but not in $\Delta h / p:$ :pMV306 (lane 3). An Invitrogen Benchmark pre-stained protein ladder was used as a molecular mass standard (lane M).

$\mathrm{mc}^{2} 155$ colonies were much larger (Fig. 2a, upper inset), with confluent colonies showing large ridges (Fig. 2a, lower inset). Colonies of the $\Delta h l p$ strain were much smaller and confluent colonies lacked prominent ridges (Fig. 2c, upper and lower insets, respectively). As colonies aged, however, diameters of the two strains became more similar (compare Fig. $2 \mathrm{~b}$ and $\mathrm{d}$ ). Two-week-old $\mathrm{mc}^{2} 155$ colonies were rough in appearance, with ridges forming across the entire surface (Fig. 2b). However, 2-week-old $\Delta h l p$ colonies had a smoother, flatter morphology (Fig. 2d). In addition, TEM analysis of 2-week-old cultures from agar surfaces showed that $\mathrm{mc}^{2} 155$ cells were two- to threefold shorter than their 

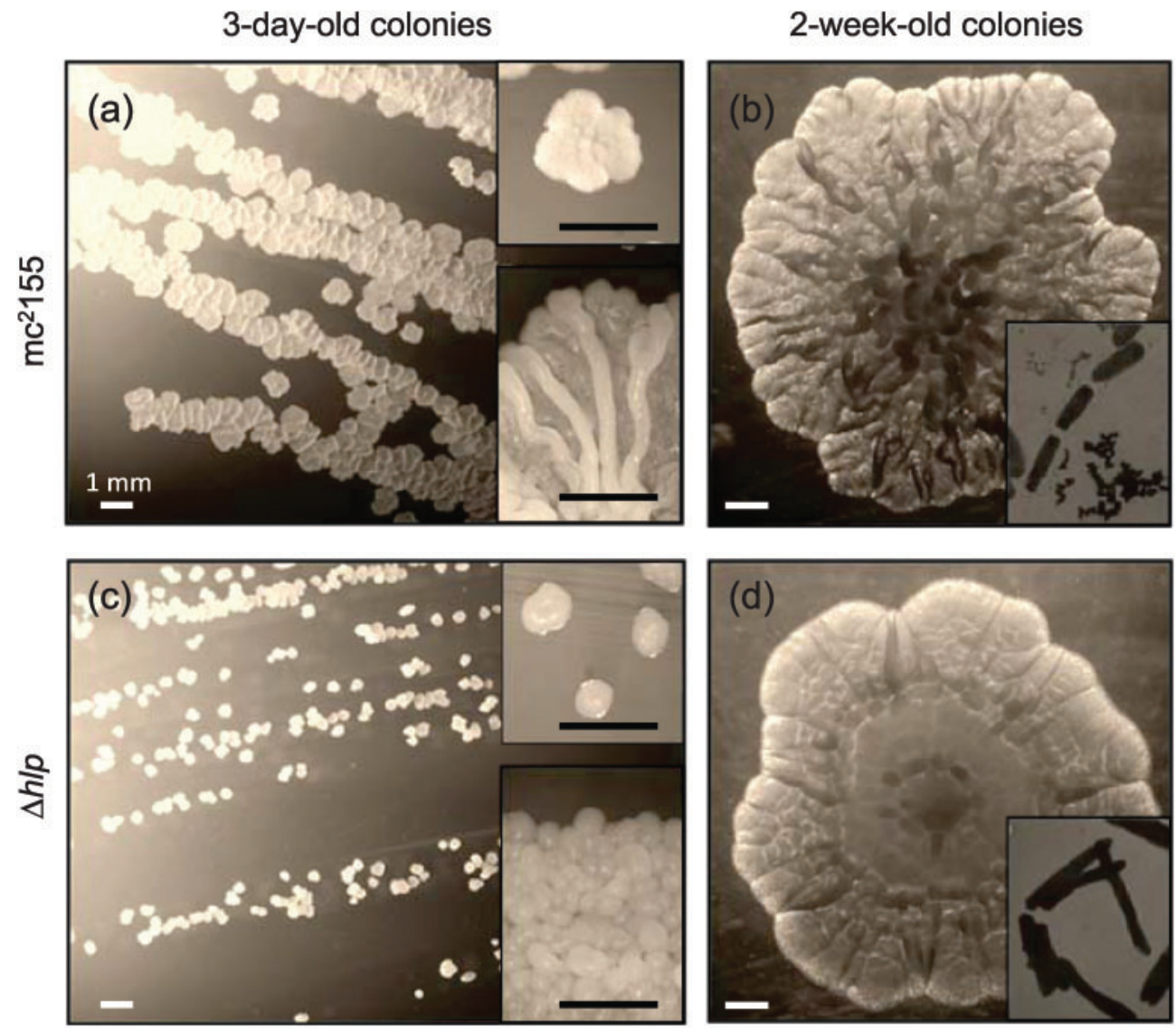

Fig. 2. Hlp affects colony and cell morphology. Strains $\mathrm{mc}^{2} 155:$ : pMV306 (a) and $\Delta h / p:$ : pMV306 (c) were grown for 3 days on 7H11 agar before visualization with a dissecting microscope. Insets show higher magnifications of individual colonies (upper insets) or of confluent colonies (lower insets). Bars, $1 \mathrm{~mm}$. Single colonies of $\mathrm{mc}^{2} 155:$ : pMV306 (b) and $\Delta h / p::$ pMV306 (d) were also allowed to continue growing for 2 weeks. TEM images $(\times 5000)$ of 2 -week-old cells are shown in the insets.

$\Delta h l p$ counterparts (compare Fig. $2 \mathrm{~b}$ and d, insets). The complemented $\Delta h l p$ mutant had the typical rough colony appearance and shortened cell morphology of $\mathrm{mc}^{2} 155$ (data not shown).

Smooth colony phenotypes in M. smegmatis have been previously reported and linked with altered cell wall hydrophobicity (Arora et al., 2008; Chen et al., 2006). Without Tween 80 , the hydrophobic nature of the $M$. smegmatis $\mathrm{mc}^{2} 155$ cell wall causes the cultures to aggregate in liquid. When M. smegmatis $\Delta h l p$ was grown in the absence of this detergent, the cells were able to grow dispersed in solution without the clumping that was seen in M. smegmatis $\mathrm{mc}^{2} 155$ (results not shown).

\section{Growth and long-term survival of $M$. smegmatis $\Delta h / p$}

Growth of $M$. smegmatis $\Delta h l p$ in $7 \mathrm{H} 9+$ Tween 80 was similar to that of M. smegmatis $\mathrm{mc}^{2} 155$ when grown at 37 or $45{ }^{\circ} \mathrm{C}$ (data not shown). Lee et al. (1998) examined the ability of an M. smegmatis hlp mutant strain to survive 2 weeks of bacterial dormancy by sustaining cultures in a low-oxygen environment. As mycobacteria are known to survive years of starvation (Sun \& Zhang, 1999), we examined changes in long-term viability for up to 8 months. Loss of $h l p$ had no effect on long-term viability in these 8-month-old, oxygen-starved cultures (results not shown).

\section{M. smegmatis $\Delta h l p$ has increased sensitivity to UV exposure}

An earlier study showed that lack of the histone-like protein HU from E. coli leads to an increase in sensitivity to UV light (Li \& Waters, 1998). This was due in part to an involvement in DNA repair processes (Miyabe et al., 2000). As a DNA-binding protein, Hlp could have an involvement in DNA repair, which might be demonstrated by alterations in UV sensitivity upon deletion of the hlp gene. Deletion of $h l p$ from M. smegmatis did result in an increase in sensitivity to UV light (Fig. 3). When exposed to up to $15 \mathrm{~J} \mathrm{~m}^{-2} \mathrm{UV}, M$. smegmatis $\Delta$ hlp::pMV306 had an eightfold decrease in survival compared with $M$. smegmatis 


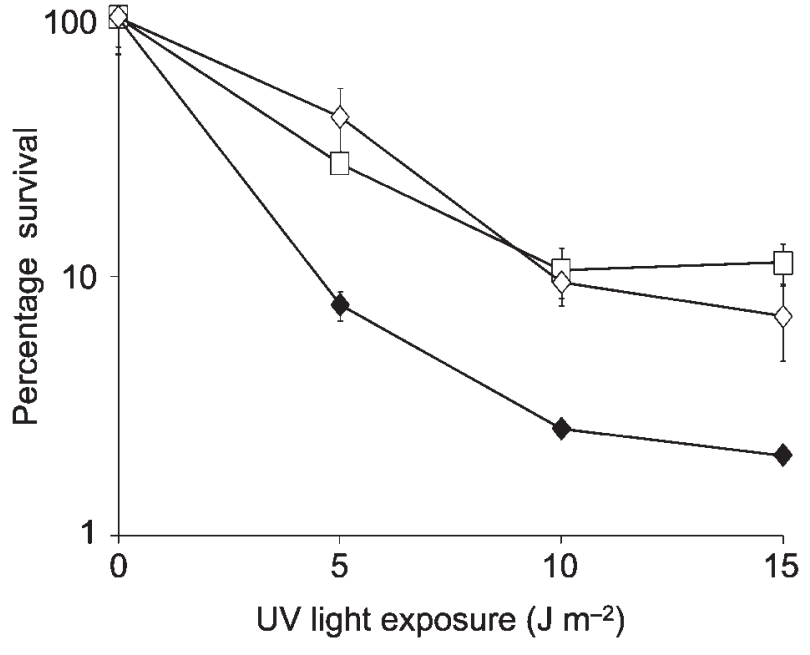

Fig. 3. Survival of $M$. smegmatis strains after exposure to UV light. Cell survival decreases with increased exposure to UV light. $\mathrm{mc}^{2} 155::$ pMV306 $(\square)$ and $\Delta h / p::$ pMV306/h/p $(\diamond)$ have eightfold increased survival compared with $\Delta h / p$ ::pMV306 ( $)$. Error bars, SD for three samples.

$\mathrm{mc}^{2} 155:$ pMV306 or the complemented mutant strain $\Delta h l p::$ pMV306/hlp.

\section{M. smegmatis $\Delta h / p$ has increased sensitivity to INH}

Previous studies have linked alteration in cell wall composition and loss of a histone-like protein to alterations in antibiotic sensitivity (Arora et al., 2008; Colangeli et al., 2007; Jackson et al., 1999; Lewin et al., 2008). To determine whether loss of Hlp generates a similar effect on antibiotic sensitivity in M. smegmatis, isogenic strains were compared for sensitivity to various antibiotics. No differences were observed between the three strains for sensitivity to kanamycin, ethambutol or rifampicin (results not shown). However, M. smegmatis $\Delta$ hlp::pMV306 showed increased sensitivity to varying concentrations of INH. The zones of INH inhibition of M. smegmatis $\Delta h l p$ were significantly larger than that of the wild-type or the complemented mutant strains (Fig. 4). The MIC for INH of M. smegmatis $\Delta h l p$ was determined to be $2.5 \mu \mathrm{g} \mathrm{ml}{ }^{-1}$, which was fourfold smaller than that observed for isogenic strains containing a functional $h l p$ gene.

\section{M. smegmatis $\Delta h / p$ has increased sensitivity to freezing}

An earlier report linked $h l p$ with the ability of $M$. smegmatis to adapt to a cold shock of $10{ }^{\circ} \mathrm{C}$ and resume growth (Shires \& Steyn, 2001). While this study looked at the ability of an $M$. smegmatis hlp mutant to gradually acclimatize to a temperature of $10{ }^{\circ} \mathrm{C}$, here we tested the ability of M. smegmatis $\Delta h l p$ to survive a rapid temperature

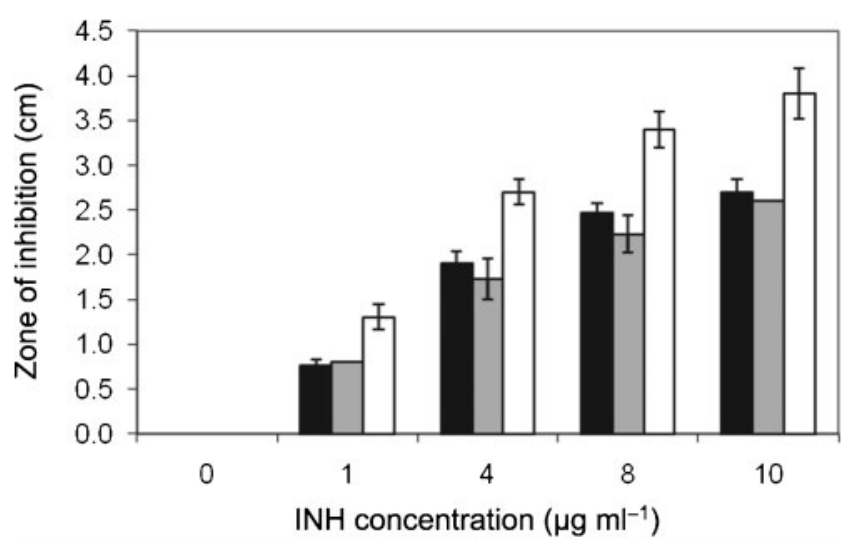

Fig. 4. Loss of $h / p$ confers increased susceptibility to INH. Zones of inhibition were measured around disks soaked with increasing concentrations of INH. Black bars, $\mathrm{mc}^{2} 155$ : : pMV306; grey bars, $\Delta h / p:$ : pMV306/h/p; white bars, $\Delta h / p:$ :pMV306. Error bars, SD for three experiments.

adjustment through repeated cycles of freezing and thawing (Fig. 5a). After 21 rounds of repeated freezing and thawing, $M$. smegmatis $\Delta h l p::$ pMV306 had a 10 -fold decrease in percentage survival compared with $\mathrm{mc}^{2} 155:$ : pMV306 and $\Delta h l p::$ pMV306/hlp.

Sphagnum peat bogs are environmental niches rich in mycobacterial diversity, and M. smegmatis can be found there (Kazda, 2000). Decaying sphagnum moss can act as a natural insulator to keep subsurface levels constant at 4$10{ }^{\circ} \mathrm{C}$ while daily surface temperatures fluctuate widely. During winter months, freezing can occur several centimetres downwards into the moss. Cryovial tubes containing different strains of M. smegmatis were incubated below the surface of sphagnum moss to let cultures be exposed to natural freezing and thawing cycles over a nine-month period. During the spring and summer months (MarchJuly), there was no observed difference in survival of the three strains (Fig. 5b). However, during the autumn and winter months, cells lacking $h l p$ experienced as much as a 100 -fold decrease in viability compared with cells expressing $h l p$ (Fig. 5c). This reduction in viability corresponds to surface and subsurface freezing temperatures. During the months of December 2009 and January 2010, average daily surface temperatures exceeded $0{ }^{\circ} \mathrm{C}$ only twice and not at all in February 2010.

\section{Survival at acidic pH}

Recently, Bi et al. (2009) showed that E. coli histone-like proteins (HU proteins) play an important role in allowing the bacteria to grow at low $\mathrm{pH}$. To test whether $M$. smegmatis can survive at lower $\mathrm{pH}$ levels in an $h l p-$ dependent fashion, isogenic strains were compared for viability after exposure to increasingly acidic media (Fig. 6). Although a decreasing viability corresponded to 
(a)
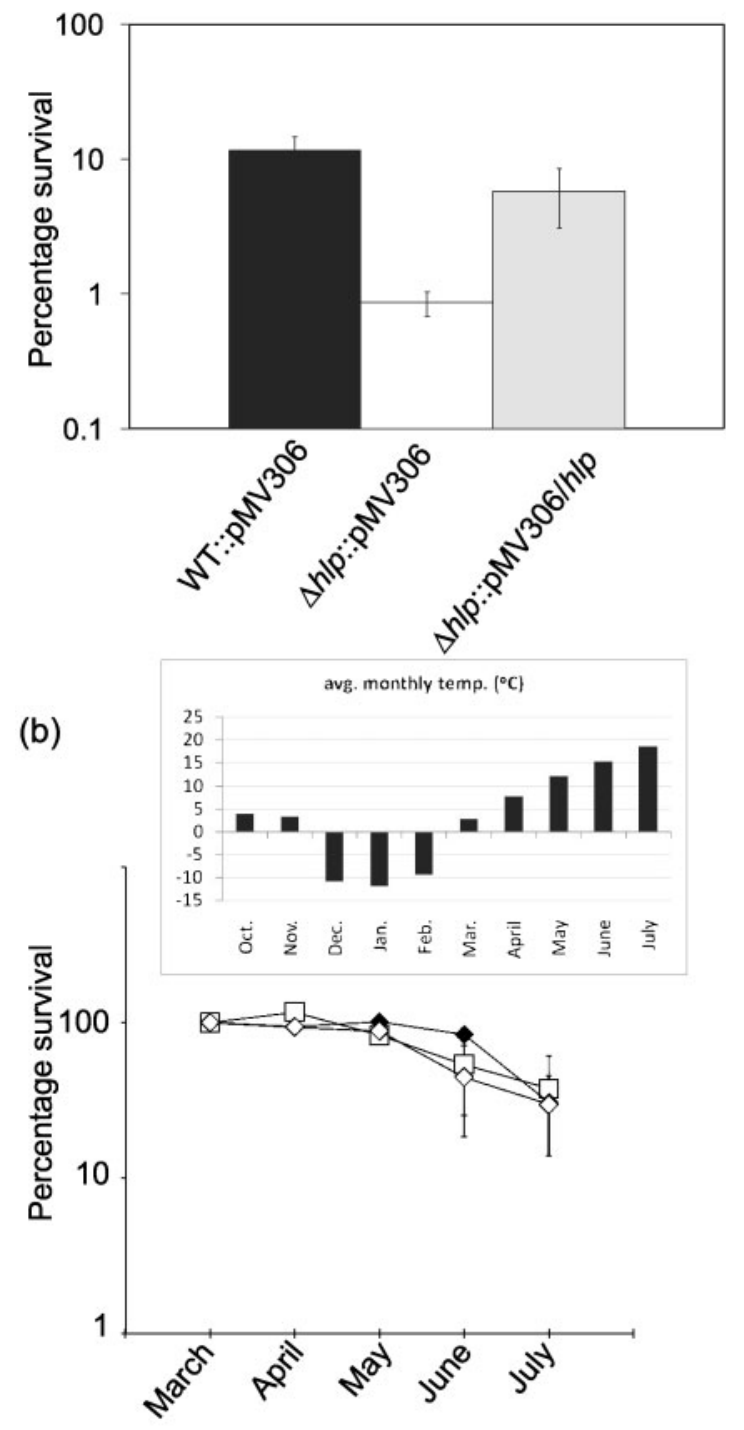

(c)

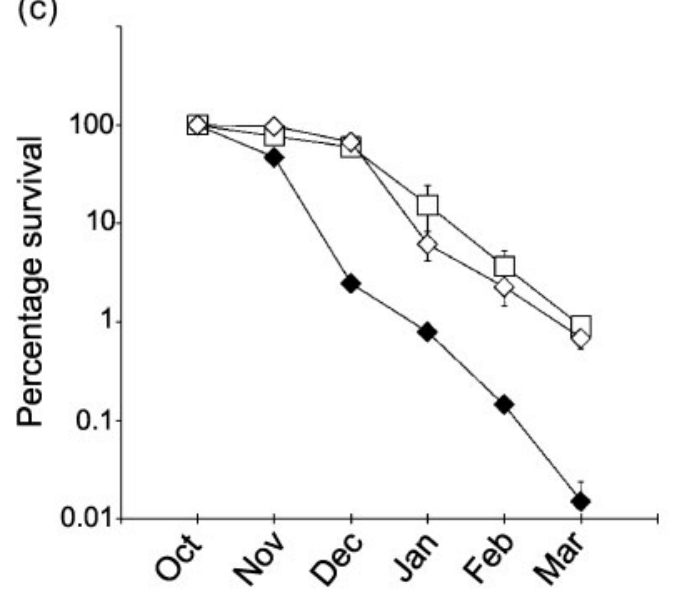

Fig. 5. Viability of $M$. smegmatis strains after repeated rounds of freezing and thawing. (a) Following 21 cycles of controlled freezing and thawing, viabilities of cultures were compared by determining c.f.u. $\mathrm{ml}^{-1} \cdot \mathrm{mc}^{2} 155:$ : pMV306 (black bar) and $\Delta h / p:$ : pMV306/h/p (grey bar) have a 10-fold enhanced survival over $\Delta h / p:$ : pMV306 (white bar). Cultures were submerged in a sphagnum moss bog for several months in spring and summer (b) or autumn and winter (c). Samples were removed at the designated months and compared for cell viabilities. $\square, \mathrm{mc}^{2} 155::$ MMV306; $\diamond, \Delta h / p::$ MV306; $\diamond$, $\Delta h / p::$ pMV306/h/p. Error bars, SD for three samples. Average monthly surface temperatures are also shown (b, insert).

(a)

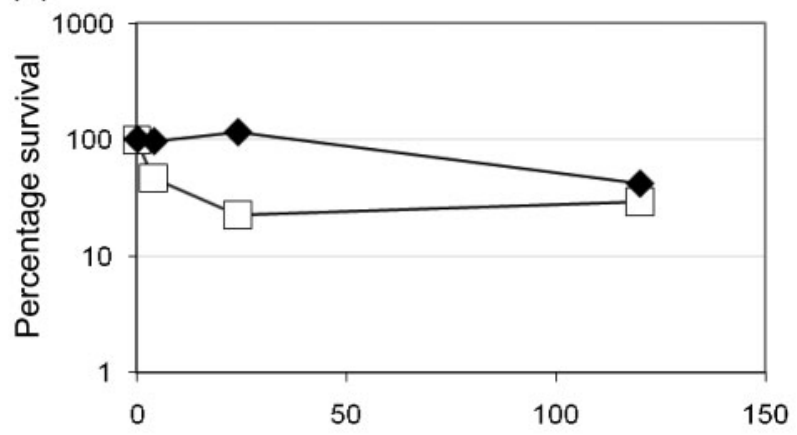

(b)

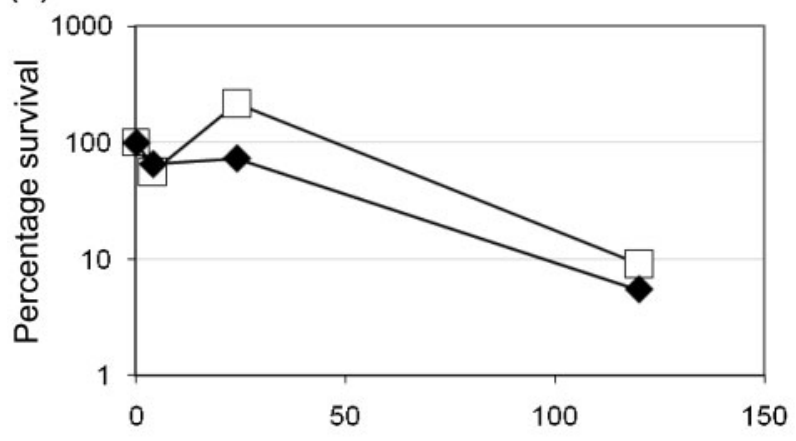

(c)

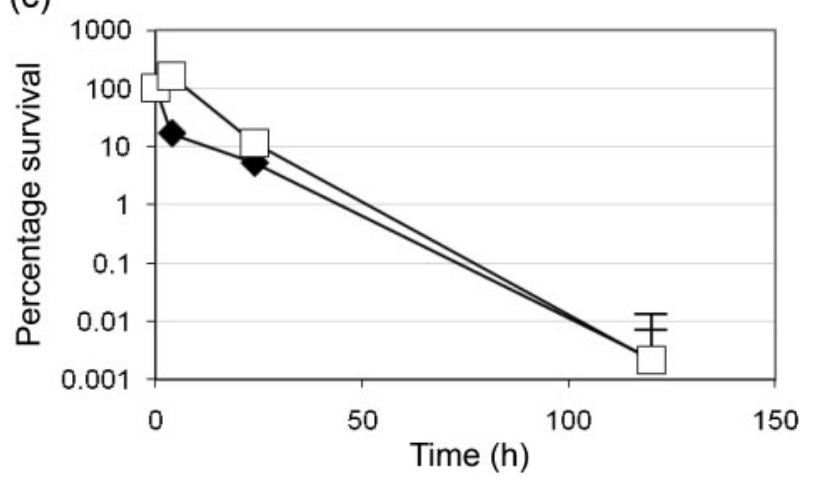

Fig. 6. Comparison of $M$. smegmatis strain survival during acid stress. Cultures of $\mathrm{mc}^{2} 155:$ :pMV306 $(\square)$ and $\Delta h / p:$ : pMV306 $(\checkmark)$ were exposed to $\mathrm{pH}$ levels of 6.5 (a), 5.0 (b) and 4.0 (c) for increasing durations before testing for viability by measuring c.f.u. $\mathrm{ml}^{-1}$ and recording this as the percentage survival of cells with respect to time 0 . Error bars, SD for three experiments. 
decreasing $\mathrm{pH}$ levels (compare Fig. $6 \mathrm{a}, \mathrm{b}$ and $\mathrm{c}$ ), there was no appreciable difference in acid tolerance between strains with or without $h l p$.

\section{DISCUSSION}

In this report we have examined the role that $h l p$ plays in stress tolerance and antibiotic sensitivity for M. smegmatis. Loss of Hlp adversely affects the ability of the organism to survive UV radiation (Fig. 3) and freezing conditions (Fig. 5). Additionally, M. smegmatis $\Delta h l p$ was more susceptible to the antibiotic INH (Fig. 4). However, the Hlp does not affect the growth rate of cells in liquid (Fig. 2a), the ability to survive hypoxia and nutrient deprivation (Fig. 2b), or the ability to withstand acidic conditions (Fig. 6).

Hlp is a small, basic, DNA-binding protein that was first characterized in $M$. smegmatis as a major protein induced in response to cellular dormancy (Lee et al., 1998). Hlp shares similarity to other prokaryotic histone-like proteins through its N-terminal domain, and to the eukaryotic histone $\mathrm{H} 1$ proteins through its C-terminal domain (Prabhakar et al., 1998). As a histone-like protein, Hlp might play roles in DNA compaction and gene regulation necessary for stress survival. The ability of Hlp to act as a transcriptional repressor in M. smegmatis in vitro means that it may regulate gene activity (Mukherjee et al., 2008), although at present the full significance of Hlp in M. smegmatis has not been elucidated. Hlp homologues have been found localized to the cytosol and nucleoid (Mukherjee et al., 2008; Prabhakar et al., 1998), and to the cell wall (Aoki et al., 2004; Soares de Lima et al., 2005; Yeruva et al., 2006). This localization suggests a complex and multifunctional role for these structurally unique mycobacterial histone-like proteins.

We have recently reported that loss of the histone-like protein Lsr2 from M. smegmatis produces a smooth colony (Arora et al., 2008; Chen et al., 2006). The deletion of hlp from the $M$. smegmatis chromosome also results in a smoother colony morphology (Fig. 2c, d). This suggests changes in the cell envelope composition. Using scanning electron microscopy, Katsube et al. (2007) showed that stationary-phase cells of an M. smegmatis hlp mutant had crenellated surfaces, unlike the smooth cell surface seen in wild-type M. smegmatis. These authors also demonstrated that Hlp was involved in the downregulation of cell surface components in stationary phase (Katsube et al., 2007). These results all appear to confirm that loss of Hlp affects the composition of the cell envelope. Such changes often coincide with differences in cell hydrophobicity (Chen et al., 2006; Ojha et al., 2005). A decrease in the hydrophobicity of $M$. smegmatis $\Delta h l p$ was evident from its ability to grow dispersed in liquid media without the addition of the detergent Tween 80 (results not shown). Given that Hlp homologues are found localized to the cell envelope (Katsube et al., 2007; Soares de Lima et al., 2005) and that Hlp can bind externally to Mycobacterium bovis (Katsube et al., 2007), it is possible that Hlp is involved in cell-to-cell aggregation of M. smegmatis. Lewin et al. (2008) found that reducing expression of the Hlp homologue in $M$. bovis decreased cell aggregation.

Because $h l p$ is upregulated in response to bacterial dormancy, Lee et al. (1998) examined the effect of the loss of Hlp on the short-term viability of oxygen-starved cultures left stationary for up to 2 weeks. While they did not observe any decrease in viability without $h l p$, $M$. smegmatis can exist in a dormant state for years. Therefore, we repeated this experiment for up to 8 months but were unable to observe any effect on long-term viability in oxygen-starved cultures due to loss of $h l p$ (results not shown). Lewin et al. (2008) have reported that there is no correlation between Hlp levels and growth rates of M. bovis under low-oxygen conditions. However, differences in protein production were observed if Hlp levels were reduced, suggesting that $\mathrm{Hlp}$ plays a role in protein expression of M. bovis BCG in hypoxic conditions. Further work is needed to determine whether the loss of Hlp in M. smegmatis affects gene expression under low oxygen.

M. smegmatis $\Delta h l p$ had an eightfold decrease in survival when subjected to UV light (Fig. 3). This is in contrast to an $M$. smegmatis $\Delta s m c$ mutant, which shows no change in levels of repair of UV-induced lesions (Güthlein et al., 2008). This is despite the role of SMC (structural maintenance of chromosomes) proteins in repair of DNA damage in different species of bacteria. In E. coli, deletion of the heterodimer formed by the histone-like proteins $\mathrm{HU} \alpha$ and $\mathrm{HU} \beta$ leads to an over 100-fold decrease in UV survival (Li \& Waters, 1998). This susceptibility to UV light in E. coli is attributed to a deficiency in RecA-dependent DNA repair and SOS induction (Miyabe et al., 2000). Although Hlp appears to play less of a protective role in M. smegmatis than in E. coli (eightfold compared with 100fold), it is possible that Hlp of M. smegmatis is also involved in DNA repair. A recent publication has demonstrated that Hlp enhances DNA end-joining in $M$. smegmatis in vitro (Mukherjee et al., 2008). An additional reason for the increased susceptibility to UV seen here in the $\Delta h l p$ strain could be the alteration in the cell envelope structure. As a major barrier against the environment, changes in the cell envelope could affect UV sensitivity. For example, the loss of genes involved in cell envelope composition in Lactococcus lactis leads to an increase in UV sensitivity (Duwat et al., 1997).

M. smegmatis $\Delta h l p$ was tested for its susceptibility to four antibiotics: INH, rifampicin, ethambutol and kanamycin. No change in the susceptibility to rifampicin, ethambutol or kanamycin was observed. This result is similar to that seen in M. bovis, where reduced expression of the Hlp homologue has no affect on the rifampicin susceptibility (Lewin et al., 2008). The loss of Hlp from M. smegmatis did lead to a fourfold increase in susceptibility to INH (Fig. 4). INH is a front-line drug for the treatment of tuberculosis, and is a small hydrophilic prodrug that enters into the cell by passive diffusion, where it is activated by the action of 
KatG (Zhang \& Telenti, 2000). Activated INH can inhibit enzymes involved in the synthesis of mycolic acids (Zhang \& Telenti, 2000). Further cellular damage can occur as a result of the action of reactive oxygen radicals, which are produced during prodrug activation (Zhang et al., 1996). With the loss of Hlp, M. smegmatis may be more susceptible to the free radicals produced by INH activation, suggesting an involvement of $\mathrm{Hlp}$ in the resistance of $M$. smegmatis to oxidative damage. It is possible that alterations in the cell wall of $M$. smegmatis $\Delta h l p$ increase cell permeability to INH. However, this does not seem likely, since no Hlp-dependent differences were seen in the sensitivities to the other antibiotics tested, including ethambutol, a similarly small hydrophilic antibiotic.

Tolerance to freeze-thaw activity is a complex mechanism involving the accumulation of trehalose, the production of molecular chaperones, and the composition of the bacterial cell wall (Tanghe et al., 2003). M. smegmatis $\Delta h l p$ has decreased tolerance to repeated freezing and thawing (Fig. 5). An earlier study demonstrated the inability of an M. smegmatis hlp mutant to resume growth after cultures were shifted from 37 to $10{ }^{\circ} \mathrm{C}$ (Shires \& Steyn, 2001). This study examined cellular viability after repeated rounds of freezing and thawing. As a major cold-shock-inducible protein, Hlp could be involved in stabilizing mRNA transcripts and allowing transcription initiation to occur after a cold shock (Shires \& Steyn, 2001). However, the method used here suggests a different role for Hlp in freeze tolerance as the cells were rapidly shifted to a state of metabolic inactivity (Fig. 5a). In lactobacilli, the fatty acid composition of the cell membrane has been linked to the tolerance of freezing and thawing (Gomez Zavaglia et al., 2000), and it is possible that the altered composition of the $M$. smegmatis $\Delta h l p$ cell envelope lowers freeze tolerance.

Attempts were made in this study to test in the laboratory the conditions that M. smegmatis would naturally encounter in a peat bog. Sphagnum moss bogs are acidic, oligotrophic, anoxic environments with poor microbial growth. Typically these environments are located in boreal and arctic regions subject to periodic annual snow cover. Although these environments provide numerous physical hindrances to microbial growth, mycobacteria are found in great abundance and diversity in the slowly decaying dead layer (grey-brown layer) several centimetres below the green, actively growing surface of the moss. Mycobacteria are not present in the green canopy of the moss because it is extremely acidic as a result of cation antiport, in which moss cells export protons in order to take up essential cations (Brennan \& Nikaido, 1995). Hpl does not appear necessary for $M$. smegmatis to tolerate low oxygen, low nutrients or low $\mathrm{pH}$, but $\mathrm{Hpl}$ is likely to help M. smegmatis withstand repeated bouts of freezing as well as penetrating UV light.

The pleiotropic phenotype of the hlp mutant suggests that some regulator mechanism has been altered. It is possible that alterations in a single cell envelope moiety could be responsible for all of the phenotypes reported here, but this seems less feasible than changes in the regulation of multiple genes due to loss of Hlp. Further study of this possibility will be conducted through microarray comparisons of the wild-type and $\Delta h l p$ strains.

\section{ACKNOWLEDGEMENTS}

We thank Christine Davitt for assistance with TEM analysis. This research was supported by internal funds from the University of Minnesota Duluth.

\section{REFERENCES}

Aoki, K., Matsumoto, S., Hirayama, Y., Wada, T., Ozeki, Y., Niki, M., Domenech, P., Umemori, K., Yamamoto, S. \& other authors (2004). Extracellular mycobacterial DNA-binding protein 1 participates in Mycobacterium-lung epithelial cell interaction through hyaluronic acid. J Biol Chem 279, 39798-39806.

Arfin, S. M., Long, A. D., Ito, E. T., Tolleri, L., Riehle, M. M., Paegle, E. S. \& Hatfield, G. W. (2000). Global gene expression profiling in Escherichia coli K12. The effects of integration host factor. J Biol Chem 275, 29672-29684.

Arora, K., Whiteford, D. C., Lau-Bonilla, D., Davitt, C. M. \& Dahl, J. L. (2008). Inactivation of $l s r 2$ results in a hypermotile phenotype in Mycobacterium smegmatis. J Bacteriol 190, 4291-4300.

Bi, H., Sun, L., Fukamachi, T., Saito, H. \& Kobayashi, H. (2009). HU participates in expression of a specific set of genes required for growth and survival at acidic $\mathrm{pH}$ in Escherichia coli. Curr Microbiol 58, 443448.

Brennan, P. J. \& Nikaido, H. (1995). The envelope of mycobacteria. Annu Rev Biochem 64, 29-63.

Chen, J. M., German, G. J., Alexander, D. C., Ren, H., Tan, T. \& Liu, J. (2006). Roles of Lse2 in colony morphology and biofilm formation of Mycobacterium smegmatis. J Bacteriol 188, 633-641.

Claret, L. \& Rouviere-Yaniv, J. (1997). Variation in HU composition during growth of Escherichia coli: the heterodimer is required for long-term survival. J Mol Biol 273, 93-104.

Colangeli, R., Helb, D., Vilcheze, C., Hazbon, M. H., Lee, C.-G., Safi, H., Sayers, B., Sardone, I., Jones, M. B. \& other authors (2007). Transcriptional regulation of multi-drug tolerance and antibioticinduced responses by the histone-like protein Lsr2 in M. tuberculosis. PLoS Pathog 3, e87.

Dahl, J. L., Kraus, C. N., Boshoff, H. I., Doan, B., Foley, K., Avarbock, D., Kaplan, G., Mizrahi, V., Rubin, H. \& Barry, C. E., III (2003). The role of RelMtb-mediated adaptation to stationary phase in long-term persistence of Mycobacterium tuberculosis in mice. Proc Natl Acad Sci U S A 100, 10026-10031.

Duwat, P., Cochu, A., Ehrlich, S. D. \& Gruss, A. (1997). Characterization of Lactococcus lactis UV-sensitive mutants obtained by ISS1 transposition. J Bacteriol 179, 4473-4479.

Gomez Zavaglia, A., Disalvo, E. A. \& de Antoni, G. L. (2000). Fatty acid composition and freeze-thaw resistance in lactobacilli. $J$ Dairy Res 67, 241-247.

Güthlein, C., Wanner, R. M., Sander, P., Bottger, E. C. \& Springer, B. (2008). A mycobacterial $s m c$ null mutant is proficient in DNA repair and long-term survival. J Bacteriol 190, 452-456.

Jackson, M., Raynaud, C., Lanéelle, A., Guilhot, C., Laurent-Winter, C., Ensergueix, D., Gicquel, B. \& Daffé, M. (1999). Inactivation of the 
antigen $85 \mathrm{C}$ gene profoundly affects the mycolate content and alters the permeability of the Mycobacterium tuberculosis cell envelope. Mol Microbiol 31, 1573-1587.

Jacobs, W. R., Jr, Tuckman, M. \& Bloom, B. R. (1987). Introduction of foreign DNA into mycobacteria using a shuttle plasmid. Nature 327, 532-535.

Katsube, T., Matsumoto, S., Takatsuka, M., Okuyama, M., Ozeki, Y., Naito, M., Nishiuchi, Y., Fujiwara, N., Yoshimura, M. \& other authors (2007). Control of cell wall assembly by a histone-like protein in mycobacteria. J Bacteriol 189, 8241-8249.

Kazda, J. (2000). The Ecology of Mycobacteria. Dordrecht, The Netherlands: Kluwer Academic Publishers.

Lee, B. H., Murugasu-Oci, B. \& Dick, T. (1998). Upregulation of a histone-like protein in dormant Mycobacterium smegmatis. Mol Gen Genet 260, 475-479.

Lewin, A., Daniela, B., Kamal, E., Bon, F., Kunisch, R., Maurischat, S., Adonopoulou, M. \& Eich, K. (2008). The mycobacterial DNA-binding protein MDP1 from Mycobacterium bovis BCG influences various growth characteristics. BMC Microbiol 8, 91-102.

Li, S. \& Waters, R. (1998). Escherichia coli strains lacking protein HU are UV sensitive due to a role of $\mathrm{HU}$ in homologous recombination. J Bacteriol 180, 3750-3756.

Matsumoto, S., Furugen, M., Yukitake, H. \& Yamada, T. (2000). The gene encoding mycobacterial DNA-binding protein I (MDPI) transformed rapidly growing bacteria to slowly growing bacteria. FEMS Microbiol Lett 182, 297-301.

Miyabe, I., Zhang, Q. M., Kano, Y. \& Yonei, S. (2000). Histone-like protein $\mathrm{HU}$ is required for $r e c A$ gene-dependent DNA repair and SOS induction pathways in UV-irradiated Escherichia coli. Int J Radiat Biol 76, 43-49.

Mukherjee, A., Bhattacharyya, G. \& Grove, A. (2008). The C-terminal domain of HU-related histone-like protein Hlp from Mycobacterium smegmatis mediates DNA end-joining. Biochemistry 47, 8744-8753.

O’Brien, L. M., Gordon, S. V., Roberts, I. S. \& Andrew, P. W. (1996). Response of Mycobacterium smegmatis to acid stress. FEMS Microbiol Lett 139, 11-17.

Ojha, A., Anand, M., Bhatt, A., Kremer, L., Jacobs, W. R., Jr \& Hatfull, G. F. (2005). GroEL1: a dedicated chaperone involved in mycolic acid biosynthesis during biofilm formation in mycobacteria. Cell 123, 861-873.

Parekh, B. S. \& Hatfield, G. W. (1996). Transcriptional activation by protein-induced DNA bending: evidence for a DNA structural transmission model. Proc Natl Acad Sci U S A 93, 1173-1177.

Parish, T. \& Stoker, N. G. (2000). Use of a flexible cassette method to generate a double unmarked Mycobacterium tuberculosis tlyA plcABC mutant by gene replacement. Microbiology 146, 1969-1975.

Prabhakar, S., Annapurna, P. S., Jain, N. K., Dey, A. B., Tyagi, J. S. \& Prasad, H. K. (1998). Identification of an immunogenic histone-like protein (HLPMtb) of Mycobacterium tuberculosis. Tuber Lung Dis 79, 43-53.

Sambrook, J., Fritsch, E. F. \& Maniatis, T. (1989). Molecular Cloning: a Laboratory Manual, 2nd edn. Cold Spring Harbor, NY: Cold Spring Harbor Laboratory.
Sassetti, C. M., Boyd, D. H. \& Rubin, E. J. (2003). Genes required for mycobacterial growth defined by high density mutagenesis. $\mathrm{Mol}$ Microbiol 48, 77-84.

Shires, K. \& Steyn, L. (2001). The cold-shock stress response in Mycobacterium smegmatis induces the expression of a histone-like protein. Mol Microbiol 39, 994-1009.

Soares de Lima, C., Zulianello, L., de Melo Marques, M. A., Kim, H., Portugal, M. I., Antunes, S. L., Menozzi, F. D., Ottenhoff, T. H., Brennan, P. J. \& Pessolani, M. C. (2005). Mapping the lamininbinding and adhesive domain of the cell surface-associated Hlp/LBP protein from Mycobacterium leprae. Microbes Infect 7, 1097-1109.

Stover, C. K., de la Cruz, V. F., Fuerst, T. R., Burlein, J. E., Benson, L. A., Bennett, L. T., Bansal, G. P., Young, J. F., Lee, M. H. \& other authors (1991). New use of BCG for recombinant vaccines. Nature 351, 456-460

Sun, Z. \& Zhang, Y. (1999). Spent culture supernatant of Mycobacterium tuberculosis H37Ra improves viability of aged cultures of this strain and allows small inocula to initiate growth. J Bacteriol 181, 7626-7628.

Swinger, K. K. \& Rice, P. A. (2004). IHF and HU: flexible architects of bent DNA. Curr Opin Struct Biol 14, 28-35.

Tanghe, A., Van Dijck, P. \& Thevelein, J. M. (2003). Determinants of freeze tolerance in microorganisms, physiological importance, and biotechnological applications. Adv Appl Microbiol 53, 129176.

Thanbichler, M., Wang, S. C. \& Shapiro, L. (2005). The bacterial nucleoid: a highly organized and dynamic structure. J Cell Biochem 96, 506-521.

Wada, M., Kano, Y., Ogawa, T., Okazaki, T. \& Imamoto, F. (1988). Construction and characterization of the deletion mutant of hupA and hupB genes in Escherichia coli. J Mol Biol 204, 581-591.

Wallace, R. J., Jr, Nash, D. R., Steele, L. C. \& Steingrube, V. (1986). Susceptibility testing of slowly growing mycobacteria by a microdilution MIC method with $7 \mathrm{H} 9$ broth. J Clin Microbiol 24, 976981.

Wei, J., Dahl, J. L., Moulder, J. W., Roberts, E. A., O'Gaora, P., Young, D. B. \& Friedman, R. L. (2000). Identification of a Mycobacterium tuberculosis gene that enhances mycobacterial survival in macrophages. J Bacteriol 182, 377-384.

Yeruva, V. C., Duggirala, S., Lakshmi, V., Kolarich, D., Altmann, F. \& Sritharan, M. (2006). Identification and characterization of a major cell wall-associated iron-regulated envelope protein (Irep-28) in Mycobacterium tuberculosis. Clin Vaccine Immunol 13, 1137-1142.

Zhang, Y. \& Telenti, A. (2000). Genetics of drug resistance in Mycobacterium tuberculosis. In Molecular Genetics of Mycobacteria, pp. 235-254. Edited by G. F. Hatfull \& W. R. Jacobs, Jr. Washington, DC: American Society for Microbiology.

Zhang, Y., Dhandayuthapani, S. \& Deretic, V. (1996). Molecular basis for the exquisite sensitivity of Mycobacterium tuberculosis to isoniazid. Proc Natl Acad Sci U S A 93, 13212-13216.

Edited by: G. R. Stewart 